\title{
Spatial pattern of soil organic carbon in desert grasslands of the diluvial-alluvial plains of northern Qilian Mountains
}

\author{
Rong YANG ${ }^{1,2,3}$, YongZhong $\mathrm{SU}^{1,2,3}$, Min WANG ${ }^{1,2,3}$, Tao WANG ${ }^{3 *}$, Xiao YANG ${ }^{1,2,3}$, GuiPing FAN ${ }^{1,2,3}$, \\ TianChang $\mathrm{WU}^{1,2,3}$ \\ ${ }^{1}$ Linze Inland River Basin Research Station, Chinese Ecosystem Research Network, Lanzhou 730000, China; \\ ${ }^{2}$ Key Laboratory of Eco-hydrology in Inland River Basin, Lanzhou 730000, China; \\ ${ }^{3}$ Cold and Arid Regions Environmental and Engineering Research Institute, Chinese Academy of Sciences, Lanzhou 730000, China
}

\begin{abstract}
The soil properties in arid ecosystems are important determinants of vegetation distribution patterns. Soil organic carbon (SOC) content, which is closely related to soil types and the holding capacities of soil water and nutrients, exhibits complex variability in arid desert grasslands; thus, it is essentially an impact factor for the distribution pattern of desert grasslands. In the present study, an investigation was conducted to estimate the spatial pattern of SOC content in desert grasslands and the association with environmental factors in the diluvial-alluvial plains of northern Qilian Mountains. The results showed that the mean values of SOC ranged from 2.76 to $5.80 \mathrm{~g} / \mathrm{kg}$ in the soil profiles, and decreased with soil depths. The coefficients of variation (CV) of the SOC were high (ranging from $48.83 \%$ to $94.67 \%$ ), which indicated a strong spatial variability. SOC in the desert grasslands of the study region presented a regular spatial distribution, which increased gradually from the northwest to the southeast. The SOC distribution had a pattern linked to elevation, which may be related to the gradient of climate conditions. Soil type and plant community significantly affected the SOC. The SOC had a significant positive relationship with soil moisture $(P<0.05)$; whereas, it had a more significant negative relationship with the soil bulk density $(\mathrm{BD})(P<0.01)$. However, a number of the variations in the SOC could be explained not by the environmental factors involved in this analysis, but rather other factors (such as grazing activity and landscape). The results provide important references for soil carbon storage estimation in this study region. In addition, the SOC association with environmental variables also provides a basis for a sustainable use of the limited grassland resources in the diluvial-alluvial plains of northern Qilian Mountains.
\end{abstract}

Keywords: soil organic carbon; spatial variability; desert grasslands; elevation; edaphic factor; Qilian Mountains

Citation: Rong YANG, YongZhong SU, Min WANG, Tao WANG, Xiao YANG, GuiPing FAN, TianChang WU. 2014. Spatial pattern of soil organic carbon in desert grasslands of the diluvial-alluvial plains of northern Qilian Mountains. Journal of Arid Land, 6(2): 136-144. doi: $10.1007 / \mathrm{s} 40333-013-0200-0$

Grasslands of various types cover approximately $25.45 \%$ of the total land area and play an important role in the global terrestrial carbon (C) cycle (Scurlock et al., 2002). Most of the $C$ in grassland ecosytems is stored in the soil; therefore, assessments of $\mathrm{C}$ stocks and changes are required to assess the role of soil organic carbon (SOC) (Conant et al., 2001; Ni, 2002; Maia et al., 2009; Nakagami et al., 2009; Piao et al.,
2009; Fang et al., 2010). However, due to high soil heterogeneity it is difficult to obtain an accurate assessment of the SOC stock (Don et al., 2007). As a result, considerable interest has been generated in assessments of the spatial variability of the SOC in different terrestrial ecosystems in recent years (Arrouays et al., 2001; Liu et al., 2006). Since geostatistics was developed in the soil science field,

\footnotetext{
*Corresponding author: Tao WANG (E-mail: yangrong@1zb.ac.cn) Received 2013-01-23; revised 2013-07-12; accepted 2013-08-04

(C) Xinjiang Institute of Ecology and Geography, Chinese Academy of Sciences, Science Press and Springer-Verlag Berlin Heidelberg 2014
} 
many studies have been specifically conducted to reveal the spatial distribution characteristics of SOC in grassland ecosystems (Evrendilek et al., 2004). Although most of the studies focus on the spatial variability of the SOC stock (Don et al., 2007; Maia et al., 2009; Fang et al., 2010; Matsuura et al., 2012), there is a lack of data in this regard, especially in grassland ecosystems. It is well known that SOC content is a determinant of SOC stock (Don et al., 2007), and its spatial distribution is closely related to changes in environmental factors (Wheeler et al., 2007; Throop and Archer, 2008). However, the relative importance of elevation, climate and edaphic factors as drivers or constraints of spatial heterogeneity of SOC content in arid desert grassland ecosystems is not well understood.

The diluvial-alluvial plains of northern Qilian Mountains, with its unique landscape pattern and climate conditions, are a typical multi-ecosystem consisting of deserts and oases in the northwest of China. In recent years, a range of efforts have been made to analyze the changes in SOC in farmland ecosystems of this region (Su and Yang, 2008; Li et al., 2009a), but very little attention has been paid to the SOC and its spatial variability in desert grassland ecosystems. Temperate desert grasslands are one of the most widespread landscape types in the diluvial-alluvial plains of northern Qilian Mountains. Because of the distant precipitation gradient and distinguishing soil types and plant communities, the SOC should present a specific distribution pattern in this region. However, few studies have addressed the spatial distribution and environmental (included the climate, vegetation, or edaphic conditions) control of SOC in desert grassland ecosystems of this region. Therefore, the objectives of this study were to 1) investigate the spatial variability of SOC in the desert grasslands of the diluvial-alluvial plains of northern Qilian Mountains, and 2) analyze the distribution pattern of SOC and the possible influencing factors (such as soil type, plant community and management strategies) with the help of statistical and geostatistical analyses. The results would not only help generate an understanding about the potential role of SOC content on $\mathrm{C}$ stock in desert grasslands, but also provide basic information for a sustainable use of the limited grassland resources in this region.

\section{Materials and methods}

\subsection{Study area}

The study was conducted in the middle of the Hexi Corridor region $\left(38^{\circ} 12^{\prime}-39^{\circ} 45^{\prime} \mathrm{N}, 98^{\circ} 29^{\prime}-101^{\circ} 56^{\prime} \mathrm{E}\right)$. The selected desert grasslands are located in the diluvial-alluvial plains of northern Qilian Mountains, and are adjacent to an agriculture oasis in the northeast. Due to agricultural land exploitation, the desert grasslands appear to be discontinuously distributed in this area. The region has a typical desert climate, according to the Köppen climatic classification (BWk), and is characterized by cold winters and hot dry summers, with an annual mean air temperature of $7{ }^{\circ} \mathrm{C}$ and mean annual precipitation of $129 \mathrm{~mm}$. The main soil types are Calcic-Orthic Aridosols, Lithic Orthic Aridosols and Alluvic Primosols developed from diluvial-alluvial materials according to the Chinese Soil Taxonomy, which are equivalent to the Aridosols and Entisols in terms of USDA soil taxonomy classification (Group of Chinese Soil Taxonomy, Institute of Soil Science, Chinese Academy of Sciences, 2001). The vegetative covers range from $5 \%$ to $15 \%$, and the predominant plant species are mainly composed of sub-shrubs, such as Achnatherum inebrians, Artemisia capillaris, Artemisia scoparia, Asterothamnus alyssoides, Carex tristachya, Nitraria sphaerocarpa, Reamura soongorica, Salsola passerine, and Sympegma regelii.

\subsection{Soil sampling and vegetation survey}

In August and September of 2011, 36 sample sites were selected for vegetation survey and soil sampling (Fig. 1). A global positioning system (GPS) was used to locate every sampling site, where latitude, longitude and elevation were recorded. In each of the 36 sample points, 10 quadrats were set up along a $100-\mathrm{m}$ line transect (the quadrat numbers were $1,2,3,4,5,6,7,8$, 9 and 10). The dominant species were surveyed in every quadrat, and the soil type was recorded. Soil samples were taken with a soil auger from interval quadrats (quadrats 1, 3, 5, 7 and 9). The sampling depth was $100 \mathrm{~cm}$ with seven layers $(0-5,5-10,10-20$, $20-30,30-50,50-70$ and $70-100 \mathrm{~cm})$. For each quadrat four samples (replicates) from the same soil layer were homogenized through hand mixing. In each of the 36 sample points, soil bulk density (BD) and soil moisture were measured with a ring sampler (fixed volume of $\left.100 \mathrm{~cm}^{3}\right)$ in an excavated soil profile $(1-\mathrm{m}$ 
depth) of quadrat 5. Five replicated ring samples were collected in each soil layer $(0-5,5-10,10-20,20-30$, $30-50,50-70$ and $70-100 \mathrm{~cm})$.

Soil samples were initially air-dried, at room temperature, before being passed through a 2-mm sieve.
Before being analyzed for SOC, samples were further ground to pass through a $0.25-\mathrm{mm}$ sieve and fine roots were removed using a rubbed glass rod. SOC was determined by dichromate oxidation of Walkley-Black (Nelson and Sommer, 1982).

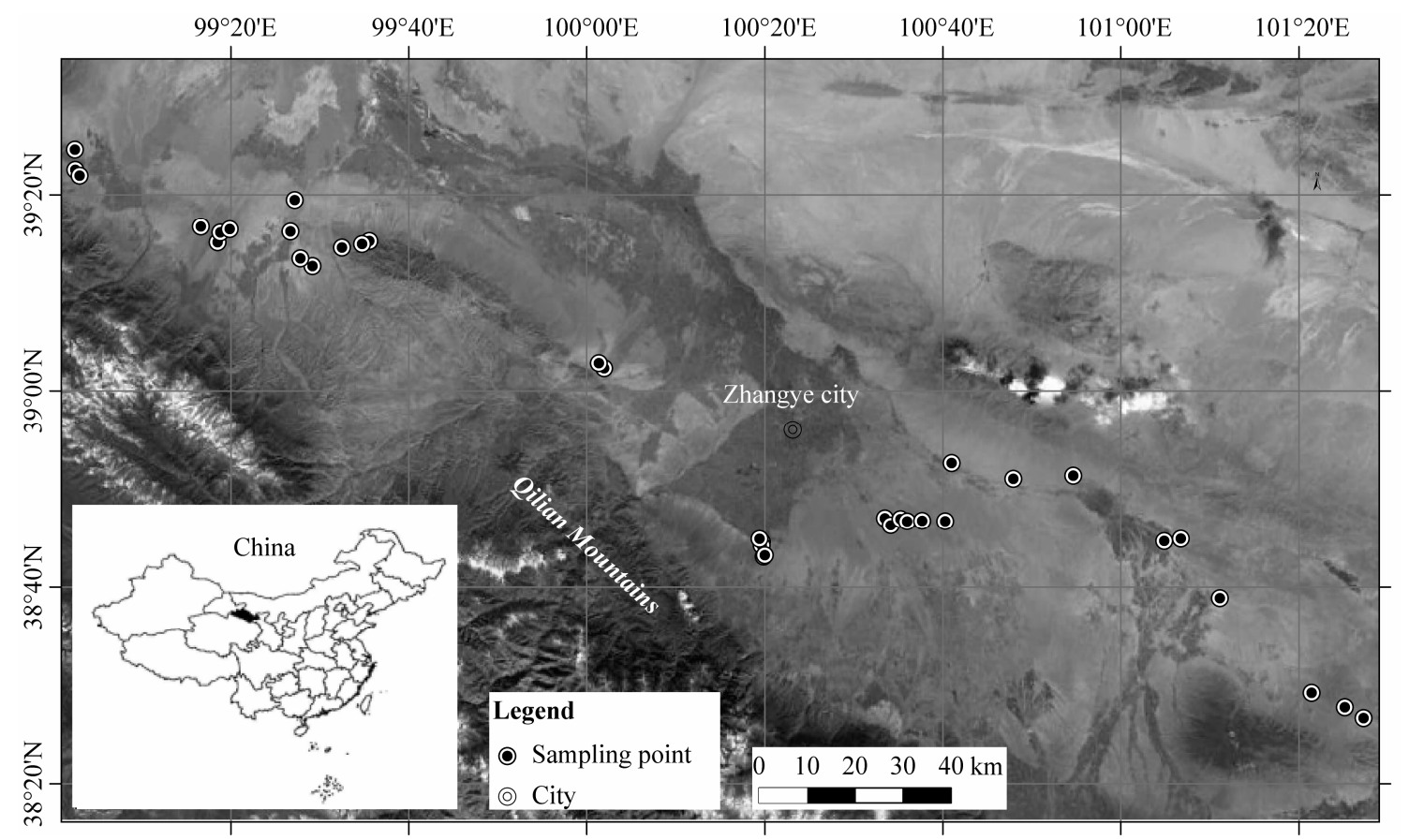

Fig. 1 The location of soil sampling points in the desert grasslands of the diluvial-alluvial plains of northern Qilian Mountains

\subsection{Statistical analysis}

Primary statistical analyses, such as frequency distributions, normality tests, regression analyses and mean comparisons, were conducted with SPSS 19.0 (Chicago, Illinois, USA). Normality of the data was assessed using the Kolmogorov-Smirnov (K-S) test. Stepwise multiple linear and logarithmic regression analyses were performed to determine the relationship between SOC and longitude, latitude, elevation, BD and soil moisture. The effect of soil types and plant communities on the SOC was determined using the general linear model (GLM). Geo-statistical analyses consisting of variogram calculation, cross-validation and Kriging were performed using the geo-statistical analyst extension of ArcGIS 10 (DSRI, California, USA).

\section{Results}

\subsection{Statistical description of SOC}

The mean values of the SOC ranged from 2.76 to 5.80 $\mathrm{g} / \mathrm{kg}$, and decreased with soil depths (Table 1). The coefficients of variation, as an index of overall variation and, therefore, of heterogeneity of SOC, were high (ranging from $48.83 \%$ to $94.67 \%$ ), suggesting dissimilarity of SOC among the samples taken from the soil profiles in the desert grasslands of the diluvial-alluvial plains of northern Qilian Mountains (Table 1).

SOC in the topsoil $(0-5 \mathrm{~cm})$ ranged from 1.85 to $16.29 \mathrm{~g} / \mathrm{kg}$, with an arithmetic mean of $5.80 \mathrm{~g} / \mathrm{kg}$. The geometric mean and median of the SOC in the topsoil were 4.89 and $5.14 \mathrm{~g} / \mathrm{kg}$, respectively (Table 1). The one-sample K-S test rejected the normal distribution (K-S, $P>0.05$ ), while the log-transformed data passed this model $(\mathrm{K}-\mathrm{S}, P<0.05)$. This implies that the SOC in the topsoil of the desert grasslands in the study region generally followed a log-normal distribution.

\subsection{Geo-statistical variability of $\mathrm{SOC}$ in topsoil}

As the log-transformed data of the SOC exhibited normal distribution for the topsoil of the desert grasslands, experimental semivariograms $(\gamma)$ were calculated from the transformed data. Statistical indices 
Table 1 Summary statistics for SOC

\begin{tabular}{|c|c|c|c|c|c|c|c|}
\hline $\begin{array}{l}\text { Soil layer } \\
\quad(\mathrm{cm})\end{array}$ & Mean & Median & $\frac{\text { Geometrical mean }}{(\mathrm{g} / \mathrm{kg})}$ & Minimum & Maximum & $\begin{array}{c}\text { Coefficient of variation } \\
(\%)\end{array}$ & Standard deviation \\
\hline $0-5$ & 5.80 & 5.14 & 4.89 & 1.85 & 16.29 & 62.07 & 3.60 \\
\hline $5-10$ & 4.32 & 3.38 & 3.58 & 1.42 & 16.15 & 94.67 & 3.20 \\
\hline $10-20$ & 3.94 & 3.25 & 3.33 & 1.50 & 13.54 & 71.32 & 2.81 \\
\hline $20-30$ & 3.48 & 2.96 & 2.95 & 1.31 & 12.03 & 68.68 & 2.39 \\
\hline $30-50$ & 3.00 & 2.63 & 2.56 & 0.94 & 11.14 & 65.33 & 1.96 \\
\hline $50-70$ & 2.99 & 2.69 & 2.62 & 0.92 & 6.60 & 52.17 & 1.56 \\
\hline $70-100$ & 2.76 & 2.43 & 2.44 & 0.73 & 5.39 & 47.83 & 1.32 \\
\hline
\end{tabular}

were used to provide quantitative analysis of the semivariogram/covariance modeling performance. The performance of the model was good when the mean standardize (MS) value was close to 0 , the root mean square (RMS) value was low, the average mean error (AME) was close to the root mean square and the root mean square standardize (RMSS) value was close to 1.0. According to the statistical indices shown in Table 2, the best-fit semivariogram model of the SOC was the Gaussian model (Fig. 2). The semivariogram of the SOC showed a longer spatial correlation along the west-east direction than in the south-north direction (Table 2). The nugget to sill ratio $\left(\mathrm{C}_{0} /\left(\mathrm{C}_{0}+\mathrm{C}\right)\right)$, shown in Table 2 , is designated by the degree of spatial heterogeneity arising from the random components to the total spatial heterogeneity. The $\mathrm{C}_{0} /\left(\mathrm{C}_{0}+\mathrm{C}\right)$ ratio ranged from $17 \%$ to $22 \%$, which indicated a strong spatial dependence for the distribution of the SOC in this study region.

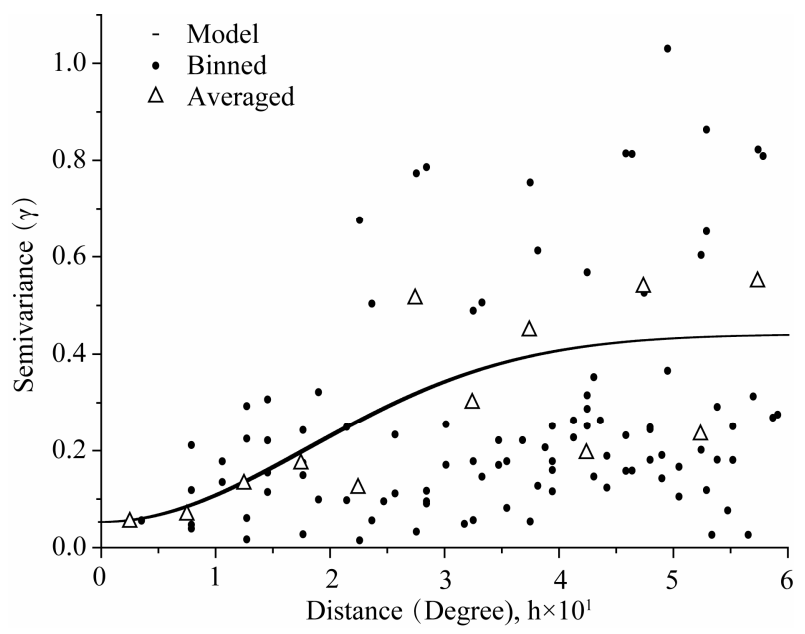

Fig. 2 Anisotropic semivariogram models for SOC in topsoil

Table 2 The semivariogram models for SOC in topsoil

\begin{tabular}{|c|c|c|c|c|c|c|c|c|c|c|c|}
\hline \multirow{2}{*}{ Model } & \multicolumn{2}{|c|}{ Range } & \multirow{2}{*}{$\begin{array}{c}\text { Angle } \\
\text { direction }\end{array}$} & \multirow{2}{*}{$\begin{array}{l}\text { Anisotropy } \\
\text { factor }\end{array}$} & \multirow{2}{*}{$\begin{array}{l}\text { Nugget } \\
\left(\mathrm{C}_{0}\right)\end{array}$} & \multirow{2}{*}{$\begin{array}{c}\text { Sill } \\
\left(\mathrm{C}_{0}+\mathrm{C}\right)\end{array}$} & \multirow{2}{*}{$\begin{array}{c}\mathrm{C}_{0} / \\
\left(\mathrm{C}_{0}+\mathrm{C}\right)\end{array}$} & \multicolumn{4}{|c|}{ Prediction errors } \\
\hline & Major axis & Minor axis & & & & & & RMS & MS & RMSS & AME \\
\hline Spherical & 0.60 & 0.30 & 111.45 & 1.99 & 0.069 & 0.32 & 0.22 & 1.73 & 0.058 & 0.68 & 2.76 \\
\hline Exponential & 0.60 & 0.40 & 110.92 & 1.51 & 0.058 & 0.35 & 0.17 & 1.76 & 0.059 & 0.67 & 2.98 \\
\hline Gaussian & 0.60 & 0.34 & 111.09 & 1.78 & 0.072 & 0.33 & 0.22 & 1.71 & 0.030 & 0.77 & 2.36 \\
\hline
\end{tabular}

\subsection{Effects of longitude, latitude and elevation on SOC}

The SOC in the topsoil was positively longitudinally correlated (Fig. 3a); while, it was negatively attitudinally correlated (Fig. 3b). This indicated that SOC has a regional distribution characteristic, and it gradually increased from the northwest to the southeast in this study region. In the desert grasslands of this study region, SOC demonstrated an obvious altitudinal gradient pattern. The result of simple linear regression analysis indicated a strong linear relationship between the elevation and the SOC (Fig. 3c).

\subsection{Effects of soil type, plant community and management strategies on SOC}

The profile distributions of the SOC among the soil samples from different soil types, plant communities and management strategies are shown in Fig. 4. According to the results of this investigation, there were three main soil types (Calcic-Orthic Aridosols, Lithic Orthic Aridosols and Alluvic Primosols), nine main 
dominant plant communities (A. inebrians, A. capillaris, A. scoparia, A. alyssoides, C. tristachya, $N$. sphaerocarpa, R. soongorica, S. passerine and S. regelii) and two main management patterns (enclosure grassland and grazing grassland) that appeared in this study region. The results showed that SOC in the profile of Calcic-Orthic Aridosols was higher than those in the profiles of Lithic Orthic Aridosols and Alluvic Primosols, and SOC contents in the profiles of $A$. capillaris communities and $C$. tristachya communities were higher than those in the profiles of other plant communities. In addition, for the grazing grassland, the SOC in the soil profile was greater than that for the enclosure grassland (Fig. 4). The GLM analysis indicated that both soil type and plant community were

most closely related to SOC, which explained 23\% and $54 \%$ of the overall variations, respectively (Table $3)$. However, the enclosure grassland did not significantly affect the SOC, and it only explained $2 \%$ of the variations in general.

\subsection{Effects of soil moisture and bulk density on SOC}

Further estimates of the effects of the two main soil factors (BD and soil moisture) on the SOC were determined by simple regression analysis (Fig. 5). The results showed that $\mathrm{BD}$ exhibited a negetive effect on the SOC in the desert grasslands of the present study. On the contrary, the soil moisure had a positive impact on the SOC distribution of the desert grasslands.

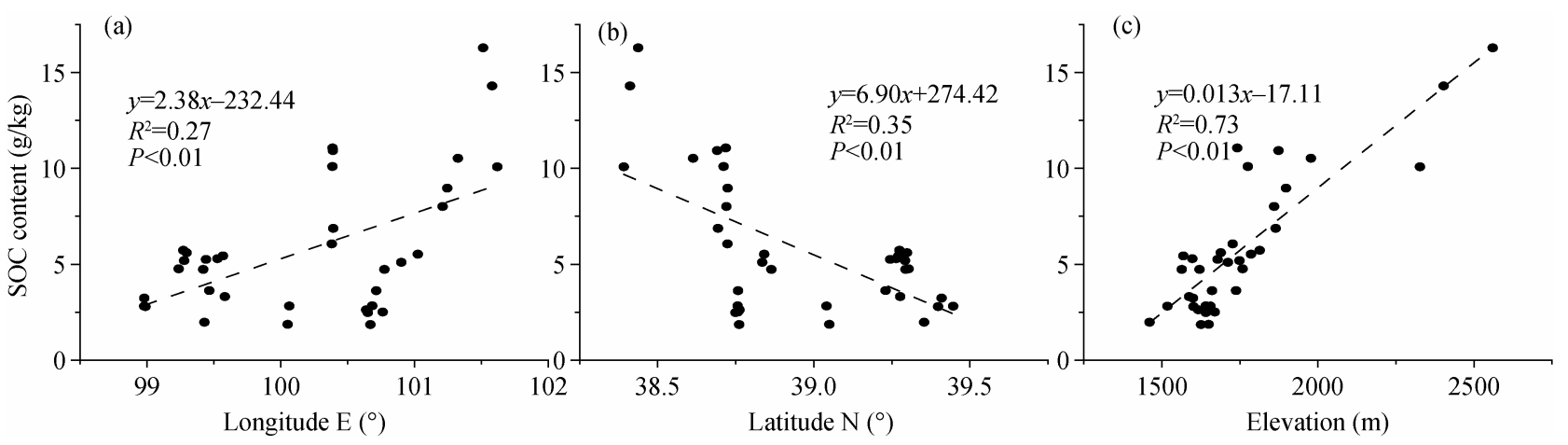

Fig. 3 Longitude (a), latitude (b), and elevation (c) effects on SOC

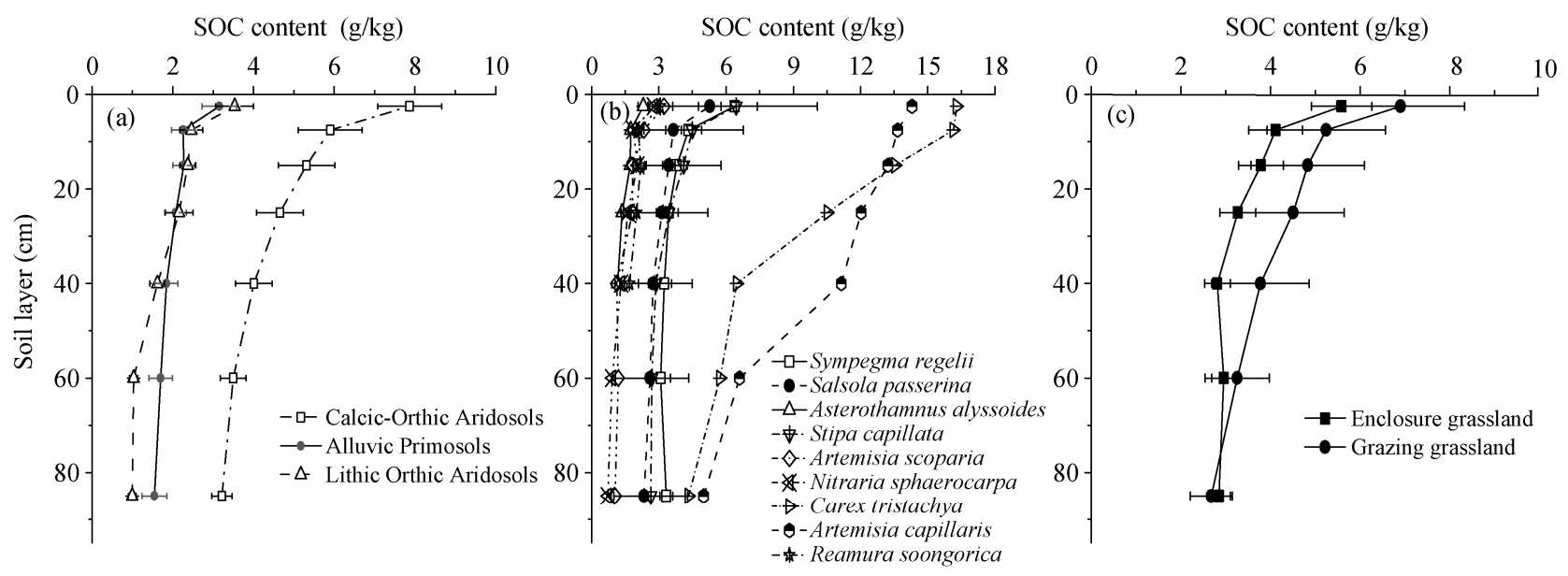

Fig. 4 Distribution of SOC in different soil types (a), plant communities (b), and management patterns (c). Mean $\pm S D$

Table 3 Summary of general linear model (GLM) of SOC as functions of soil types and plant communities

\begin{tabular}{lccrrr}
\hline Factor & Degree freedom $(d f)$ & Mean square (MS) & $F$ value & Significance level & $\begin{array}{c}\text { Partial } \\
\text { eta-squared }\end{array}$ \\
\hline Soil type & 2 & 196.90 & 33.22 & 0.00 & 0.23 \\
Plant community & 9 & 102.57 & 27.97 & 0.00 & 0.54 \\
Management strategy & 1 & 16.44 & 0.12 & 0.12 \\
\hline
\end{tabular}




\section{Discussion}

\subsection{Spatial patterns of SOC in desert grasslands}

A commonly used traditional geo-statistical tool for describing spatial data in the ecological field is semivariogram analysis (Robertson, 1987; Rossi et al., 1992). In the study, semivariogram analysis was used to describe the spatial patterns of the SOC in desert grasslands of the diluvial-alluvial plains of the northern Qilian Mountains. The semivariogram of SOC showed a longer spatial correlation along the west-east direction than in the south-north direction (Table 2), which indicated that the change of SOC in the former direction was more regular than in the latter direction. The $\mathrm{C}_{0} /\left(\mathrm{C}_{0}+\mathrm{C}\right)$ ratios were smaller than $25 \%$, which demonstrated that the spatial heterogeneity was mainly due to systematic variability, and the SOC had a strong spatial correlation (Cambardella et al., 1994). This suggested that the SOC followed a regular spatial distribution in the desert grasslands. From the regression analysis between the SOC and the longitude-latitude (Fig. 3), an apparent gradient of the SOC distribution was also found. It can be concluded that SOC increased gradually from the northwest to southeast in the desert grasslands of the diluvial-alluvial plains of northern Qilian Mountains.

\subsection{Comparisons of SOC with other temperate grasslands and the landscape types in Hexi Corridor}

Temperate grasslands are widely distributed in the northwest of China, such as Xinjiang, Gansu and Inner Mongolia. Based on inventory data or field measurements, different conclusions about the distribution characteristics of SOC have been reported in temperate grasslands of different study regions (Table 4). In this study, the mean values of SOC ranged from 2.76 to $5.80 \mathrm{~g} / \mathrm{kg}$ in the $0-100 \mathrm{~cm}$ soil profile, which is reasonably close to the results from desert grasslands of the north piedmont of Bogeda Peak (Sun et al., 2009) and Alxa desert grasslands of Inner Mongolia (Fu et al., 2002; Table 4). The values of the SOC in the present study were lower than those reported by Qi et al. (2010) from Xilin River Basin of Inner Mongolia and by Song et al. (2012) from Duolun of Inner Mongolia. These differences could be an effect of the significant spatial heteroneity across the temperate grasslands of China. Although the vegetation type was uniform, and soil types and climate conditions
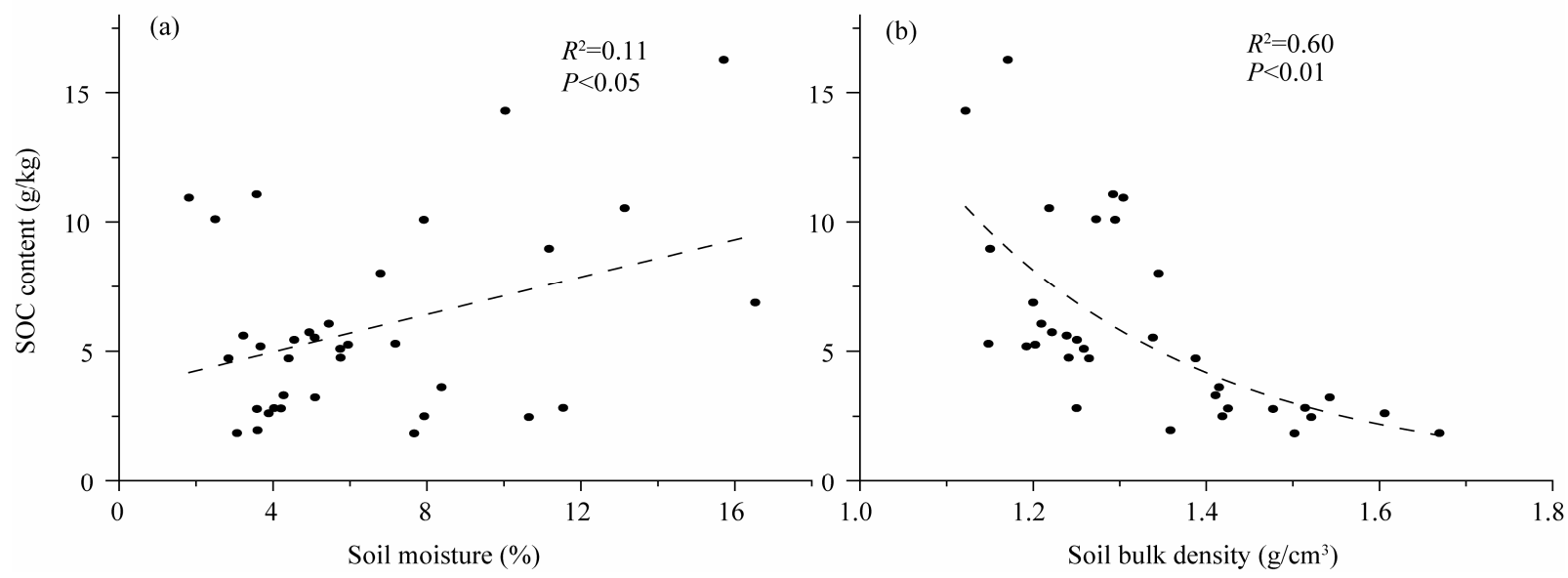

Fig. 5 Moisture (a) and soil bulk density (b) effects on spatial distribution of SOC

Table 4 Comparison of SOC with other temperate grasslands in China

\begin{tabular}{|c|c|c|c|}
\hline Region & SOC content $(\mathrm{g} / \mathrm{kg})$ & $\mathrm{AP}(\mathrm{mm})$ & Reference \\
\hline Xinjiang (north piedmont of Bogeda Peak) & $3.79-4.61$ & 236 & (Sun et al., 2009) \\
\hline Inner Mongolia (Alxa) & $2.67-3.02$ & $50-150$ & (Fu et al., 2002) \\
\hline Inner Mongolia (Xilin River Basin) & $15.18-22.13$ & $250-450$ & (Qi et al., 2010) \\
\hline Inner Mongolia (Duolun) & 18.48 & 382.3 & (Song et al., 2012) \\
\hline
\end{tabular}

Note: AP, annual precipitaion. 
could be different, and the precipitation effect on SOC could be found. From the data in Table 4, an increasing trend in the SOC can be observed as annual precipitation increased. However, much work still needs to be done regarding this topic.

Other estimates for SOC from agricultural and Gobi desert ecosystems have been determined in this study region. For example, Liu et al. (2011) reported that the mean SOC of arable soil was $7.98 \mathrm{~g} / \mathrm{kg}$, whereas the mean SOC of the Gobi desert soil was $0.79 \mathrm{~g} / \mathrm{kg}(\mathrm{Su}$ and Yang, 2008). The SOC in the desert grasslands was lower than that in the arable soil, but was higher than that in the Gobi desert soil. A greater SOC in arable soil than in desert grasslands has been reported previously ( $\mathrm{Li}$ et al., 2009b). This can be explained by the higher productivity and nutrient input in arable soil than in desert grasslands, resulting in an increased organic carbon supply.

\subsection{Determining factors for spatial distribution of SOC in desert grasslands}

The SOC increased as the elevation increased in the desert grasslands in this study region (Fig. 3). This altitudinal distribution pattern of SOC is in accordance with the studies of Powers and Schlesinger (2002) and Nyssen et al. (2008), who reported that elevation was able to explain much of the variability of soil carbon content. The elevational distribution pattern of SOC may be related to changes in climate conditions (Djukic et al., 2010). Kane et al. (2005) reported that the SOC increased as the temperature decreased and Yang et al. (2008) reported that the variation in SOC of grasslands corresponded to the precipitation gradient. Another study demonstrated that accumulation of SOC at a high altitude mainly depends on the slower decomposition rate, which is related to the lower soil temperature and higher soil moisture in high altitude regions ( $\mathrm{Bu}$ et al., 2012). In this study region, the precipitation presented a similar distribution trend to the evelation, while the atmospheric temperature presented an opposite distribution trend (Ding et al., 1996; Li et al., 2008; Yang et al., 2009; Jia, 2010). Therefore, it can be concluded that precipitation and temperature considerably contribute to the altitudinal distribution pattern of SOC in the region. A significant relationship between soil moisture and SOC was not observed in this study. This could be due to the fact that soil moisture data only represented the transient soil water conditions during the investigation (in August and September of 2011). Obviously, a full year of soil moisture data would be absolutely necessary for the accurate estimatation of the relationship between soil moisture and SOC.

A lot of studies have reported the effect of soil and vegetation on SOC (Schimel et al., 1994; Liu et al., 2006; $\mathrm{Hu}$ et al., 2007; Matsuura et al., 2012). The present study confirmed that soil type and plant community have significant effects on the SOC of desert grasslands. From the three soil types observed in the 36 sample sites, the Calcic-Orthic Aridosols soil has a higher SOC than the Lithic Orthic Aridosols and Alluvic Primosols soils. Furthermore, most of the Calcic-Orthic Aridosols were distributed in the southeast of this study region, where there were high elevations, high precipitations and low temperatures. This indicated a climate effect on the formation of the soil. In addition, a strong negative logarithm function between SOC and BD was confirmed, which was also reported by another study ( $\mathrm{Xu}$ et al., 2011), and these results showed a very similar trajectory change between SOC and BD. The function established here can be used for desert grasslands where the BD is often absent. Compared with the sampling sites dominated by subshrubs (such as $S$. passerine, S. regelii and $A$. alyssoides) and shrubs (such as $R$. soongorica and $N$. sphaerocarpa), the soil had a higher SOC in the sample sites dominated by renascent herbs (such as $A$. inebrians, A. capillaris and C. tristachya) and annual herbs (such as A. scoparia). SOC depends on the balance between organic matter input and loss of the soil. Litter falling on the soil and turnover of fine roots are regarded as the main pathways for SOC input into natural ecosystems (Li and Zhao, 2001). From this, it is possible to deduce two possible explanations for the different plant communities having different SOC. First, the high productivity of renascent herbs provides a higher input of SOC. Second, more organic matter was decomposed in the soil dominated by herb plants, which offer more perishable litter fall and fine roots than by subshrubs and shrubs.

However, soil type and plant community can only explain $23 \%$ and $54 \%$ of the variations in SOC, respectively. A large fraction of the variations in SOC could not be explained by the environmental factors involved in this analysis, indicating that other factors (such as grazing activity or landscape) possibly have strong effects on SOC. Previous studies found strong 
grazing effects on the SOC of grasslands (McSherry and Ritchie, 2013). In the present study, the enclosure grassland did not have a significant effect on SOC, and it can explain only $2 \%$ of the variations. The possible reason may be that the enclosure management did not prevent grazing activities in this study region, or the enclosure time was not sufficiently long to affect the SOC of the grasslands. Garcia-Pausas et al. (2007) reported that topographic positions (aspect and slope) are important factors for accurate estimations of $\mathrm{C}$ stocks in grassland soils. This indicates that the understanding of SOC distribuiton in the desert grasslands of the diluvial-alluvial plains of northern Qilian Mountains requires more environment factors to be taken into account.

Understanding the spatial variability of SOC relative to environmental factors, such as climate, soil and vegetation conditions is critical for assessing current and future patterns of carbon budgets in desert grasslands. Traditional methods that fail to account for the spatial pattern of SOC have serious potential limitations for assessing SOC pools in grassland ecosystems. Therefore, the results from this study can offer important basic information related to the regional assessment of $\mathrm{C}$ balances in the desert grasslands of the diluvial-alluvial plains of northern Qilian Mountains.

\section{Conclusions}

In the desert grasslands of the diluvial-alluvial plains

\section{References}

Arrouays D, Deslais W, Badeau V. 2001. The carbon content of topsoil and its geographical distribution in France. Soil Use and Management, 17: 7-11.

Bu X L, Ruan H H, Wang L M, et al. 2012. Soil organic matter in density fractions as related to vegetation changes along an altitude gradient in the Wuyi Mountains, southeastern China. Applied Soil Ecology, 52: $42-47$.

Cambardella C A, Moorman T B, Novak J M, et al. 1994. Field-scale variability of soil properties in central iowa soils. Soil Science Society of America Journal, 58: 1501-1511.

Conant R T, Paustian K, Elliott E T. 2001. Grassland management and conversion into grassland: effects on soil carbon. Ecological Applications, 11: 343-355.

Ding Y J, Ye B S, Zhou W J. 1996. Temporal and spatial precipitation distribution in the Heihe catchment, Northwest China, during the past 40 a. Journal of Glaciology and Geocryology, 21: 42-48. of northern Qilian Mountains, the spatial pattern of SOC content was investigated. The SOC was concentrated in the topsoil, and presented strong spatial variability in the desert grasslands of the study region. The SOC presented a regular spatial distribution, increasing gradually from the northwest to the southeast. The distribution of SOC had an obvious elevational pattern, which might be related to the climate gradient in this region. The distribution of SOC was also controlled by edaphic factors (such as soil type, BD, and soil moisture) and vegetation conditions (such as dominant plant community) in the desert grasslands. However, a number of the variations in the SOC could be explained not by the environmental factors involved in this analysis, but rather other factors (such as grazing activity and landscape). The results provide an important reference for the estimation of soil carbon storage in this region. In additon, SOC distribution associated with environmental variables offers basic information for a sustainable use of the limited grassland resources in the desert grasslands of this region.

\section{Acknowledgments}

This study was funded by the Strategic Priority Research Program of the Chinese Academy of Sciences (XDA05050406-3) and the National Natural Science Foundation of China (41201284 and 91125022). We thank all staff of the Linze Inland River Basin Research Station, Chinese Academy of Sciences for their participation in our field work. We also gratefully acknowledge the anonymous reviewers for their valuable comments on the manuscript.

Djukic I, Zehetner F, Tatzber M, et al. 2010. Soil organic-matter stocks and characteristics along an Alpine elevation gradient. Journal of Plant Nutrition and Soil Science, 173: 30-38.

Don A, Schumacher J, Scherer-Lorenzen M, et al. 2007. Spatial and vertical variation of soil carbon at two grassland sites-implications for measuring soil carbon stocks. Geoderma, 141: 272-282.

Evrendilek F, Celik I, Kilic S. 2004. Changes in soil organic carbon and other physical soil properties along ajacent Mediterranean forest, grassland, and cropland ecosystems. Journal of Arid Environments, 59: 743-752.

Fang J Y, Yang Y H, Ma W H, et al. 2010. Ecosystem carbon stocks and their changes in China's grasslands. Science in China: Life Sciences, 53: 757-765.

Fu H, Wang Y R, Wu C X, et al. 2002. Effects of grazing on soil physical and chemical properties of Alxa desert grassland. Journal of Desert Research, 22: 339-343. 
Garcia-Pausas J, Casals P, Camarero L, et al. 2007. Soil organic carbon storage in mountain grasslands of the Pyrenees: effects of climate and topography. Biogeochemistry, 82: 279-289.

Hu K L, Li H, Li B G, et al. 2007. Spatial and temporal patterns of soil organic matter in the urban-rural transition zone of Beijing. Geoderma, 141: 302-310.

Jia W X. 2010. Study on the relationships between regional climatic difference, geographical location and terrain in the Qlian Mountains. Arid Zone Research, 27: 607-615.

Kane E S, Valentine D W, Schuur E A G, et al. 2005. Soil carbon stabilization along climate and stand productivity gradients in black spruce forests of interior Alaska. Canadian Journal of Forest Research-Revue Canadienne De Recherche Forestiere, 35: 2118-2129.

Li F L, Li J Z, Liu Y. 2008. Spatial distribution of land surface temperature in Qilian mountain area based on MODIS. Arid Meteorology, 26: 41-47.

Li X G, Li Y K, Li F M, et al. 2009a. Changes in soil organic carbon, nutrients and aggregation after conversion of native desert soil into irrigated arable land. Soil \& Tillage Research, 104: 263-269.

Li X G, Zhang P L, Yin P, et al. 2009b. Soil organic carbon and nitrogen fractions and water-stable aggregation as affected by cropping and grassland reclamation in an arid sub-alpine soil. Land Degradation \& Development, 20: 176-186.

Li Z, Zhao Q G. 2001. Organic carbon content and distribution in soils under different land uses in tropical and subtropical China. Plant and Soil, 231: 175-185.

Liu D W, Wang Z M, Zhang B, et al. 2006. Spatial distribution of soil organic carbon and analysis of related factors in croplands of the black soil region, Northeast China. Agriculture Ecosystems \& Environment, 113: 73-81.

Liu W J, Su Y Z, Yang R, et al. 2011. Temporal and spatial variability of soil organic matter and total nitrogen in a typical oasis cropland ecosystem in arid region of Northwest China. Environmental Earth Sciences, 64: 2247-2257.

Maia S M F, Ogle S M, Cerri C E P, et al. 2009. Effect of grassland management on soil carbon sequestration in Rondônia and Mato Grosso states, Brazil. Geoderma, 149: 84-91.

Matsuura S, Sasaki H, Kohyama K. 2012. Organic carbon stocks in grassland soils and their spatial distribution in Japan. Grassland Science, 58: 79-93.

McSherry M E, Ritchie M E. 2013. Effects of grazing on grassland soil carbon: a global review. Global Change Biology, 19: 1347-1357.

Nakagami K, Hojito M, Itano S, et al. 2009. Soil carbon stock in typical grasslands in Japan. Grassland Science, 55: 96-103.

Nelson D W, Sommer L E. 1982. Total carbon, organic, and organic matter. In: Page A L. Methods of Soil Analysis. Madison: American Society of Agronomy, 539-579.

Ni J. 2002. Carbon storage in grasslands of China. Journal of Arid
Environments, 50: 205-218.

Nyssen J, Temesgen H, Lemenih M, et al. 2008. Spatial and temporal variation of soil organic carbon stocks in a lake retreat area of the Ethiopian Rift Valley. Geoderma, 146: 261-268.

Piao S L, Fang J Y, Ciais P, et al. 2009. The carbon balance of terrestrial ecosystems in China. Nature, 458: 1009-1013.

Powers J S, Schlesinger W H. 2002. Relationships among soil carbon distributions and biophysical factors at nested spatial scales in rain forests of northeastern Costa Rica. Geoderma, 109: 165-190.

Qi Y C, Dong Y S, Liu L X, et al. 2010. Spatial-temporal variation in soil respiration and its controlling factors in three steppes of Stipa L. in Inner Mongolia, China. Science in China: Earth Sciences, 53: 683-693.

Robertson G P. 1987. Geostatistics in ecology: interpolating with known variance. Ecology, 68: 744-748.

Rossi R E, Mulla D J, Journel A G, et al. 1992. Geostatistical tools for modeling and interpreting ecological spatial dependence. Ecological Monographs, 62: 277-314.

Schimel D S, Braswell B H, Holland E A, et al. 1994. Climatic, edaphic, and biotic controls over storage and turnover of carbon in soils. Global Biogeochemical Cycles, 8: 279-293.

Scurlock J M O, Johnson K, Olson R J. 2002. Estimating net primary productivity from grassland biomass dynamics measurements. Global Change Biology, 8: 736-753.

Song B, Niu S L, Zhang Z, et al. 2012. Light and heavy fractions of soil organic matter in response to climate warming and increased precipitation in a temperate steppe. PloS One, 7: 217-233.

Su Y Z, Yang R. 2008. Background concentrations of elements in surface soils and their changes as affected by agriculture use in the desert-oasis ecotone in the middle of Heihe River Basin, North-west China. Journal of Geochemical Exploration, 98: 57-64.

Sun Z J, An S Z, Duan J J. 2009. Effect of enclosure on vegetation and soil nutrient of Sagebrush desert grassland in Xinjiang. Arid Zone Research, 26: 877-882.

Throop H L, Archer S R. 2008. Shrub (Prosopis velutina) encroachment in a semidesert grassland: spatial-temporal changes in soil organic carbon and nitrogen pools. Global Change Biology, 14: 2420-2431.

Wheeler C W, Archer S R, Asner G P, et al. 2007. Climatic/edaphic controls on soil carbon/nitrogen response to shrub encroachment in desert grassland. Ecological Applications, 17: 1911-1928.

$\mathrm{Xu} \mathrm{X}$, Liu W, Zhang C, et al. 2011. Estimation of soil organic carbon stock and its spatial distribution in the Republic of Ireland. Soil Use and Management, 27: 156-162.

Yang X L, Ding W K, Dong A X, et al. 2009. Distribution and utilization of climate resources in Gansu Corridor. Chinese Journal of Agrometorology, 30: 1-5.

Yang Y H, Fang J Y, Tang Y H, et al. 2008. Storage, patterns and controls of soil organic carbon in the Tibetan grasslands. Global Change Biology, 14: 1592-1599. 